\title{
Individual differences in the obligatory activation of addition facts
}

\author{
JO-ANNE LEFEVRE and ALISON G. KULAK \\ Carleton University, Ottawa, Ontario, Canada
}

\begin{abstract}
In two experiments, we found evidence for individual differences in the obligatory activation of addition facts. Subjects were required to verify the presence of a target digit (e.g., 4) in a previously presented pair (e.g., 5+4). Subjects rejected targets that formed the sum of the initial pair (e.g., 5+4 and 9) more slowly than they rejected unrelated targets (e.g., 5+4 and 7). This interference of the sum was largest for subjects who were relatively skilled at multidigit arithmetic. Less skilled subjects did not show statistically significant effects of obligatory activation. In comparison with less skilled subjects, skilled subjects showed differential interference on plus-one (e.g., $3+1$ ) and standard (e.g., $2+3$ ) problems when the plus sign was presented, and on ties (e.g., 2 2) when the plus sign was omitted. These results suggest that network models of arithmetic fact retrieval are appropriate for skilled subjects, but that alternative models need to be considered for less skilled individuals.
\end{abstract}

Skilled performance on complex cognitive tasks is assumed to involve fast, accurate, and automatic activation of component knowledge and processes. Thus, performance on complex arithmetic problems should be facilitated by automatic activation of basic arithmetic facts (e.g., $3+4=7$; Kaye, 1986; Resnick \& Ford, 1981). There is little direct evidence, however, regarding the relation between automaticity and skill in the domain of arithmetic (Ashcraft, Donley, Halas, \& Valaki, 1992; Kaye, deWinstanley, Chen, \& Bonnefil, 1989). Consequently, the goal of the present research was to examine the relation between automaticity of arithmetic-fact retrieval and skill at solving multidigit arithmetic problems.

\section{Automaticity in Arithmetic}

Ashcraft $(1982,1987,1990)$ has proposed that arithmetic facts are stored in an associative network and that adults retrieve a fact from the network when they are presented with a simple arithmetic problem (see also Campbell, 1987a, 1987b, 1991; Campbell \& Clark, 1989; Campbell \& Graham, 1985; Campbell \& Oliphant, 1992; Widaman, Geary, Cormier, \& Little, 1989). With extensive practice, retrieval of stored arithmetic knowledge from the network is assumed to become automatic (Ashcraft, 1987). Thus, individuals who are skilled at arith-

This research was supported by the Natural Sciences and Engineering Research Council of Canada by a grant to J.L. Experiment 1 was presented at the annual meeting of the Canadian Psychological Association in Ottawa, May 1990. We thank Stephanie Greenham for her assistance with Experiment 2. Mark Ashcraft, Jeffrey Bisanz, Stephanie Greenham, Chris Herdman, Michael McCloskey, Kevin Miller, and Mike Thibodeau provided helpful comments on earlier versions of this manuscript. A.G.K. is now at Wilfrid Laurier University. Correspondence concerning this research should be sent to J.-A. LeFevre, Department of Psychology, Carleton University, Ottawa, ON, Canada K1S 5B6. (e-mail: jlefevre@ccs.carleton.ca). metic should show fast, accurate, and obligatory activation of stored facts, and retrieval should require few cognitive resources (Hasher \& Zacks, 1979; Logan, 1985, 1988; Shiffrin \& Schneider, 1977).

Research on skill differences in the automaticity of arithmetic-fact retrieval has been limited to comparisons between children and adults. First, adults and older children retrieve facts faster and more accurately than younger children do (see, e.g., Ashcraft \& Fierman, 1982; Groen \& Parkman, 1972; Hamann \& Ashcraft, 1985; Miller \& Paredes, 1990; Stazyk, Ashcraft, \& Hamann, 1982; Widaman, Little, Geary, \& Cormier, 1992). Second, adults show evidence for obligatory (unintentional) activation of arithmetic knowledge (LeFevre, Bisanz, \& Mrkonjic, 1988; LeFevre, Kulak, \& Bisanz, 1991; Stazyk et al., 1982; Winkelman \& Schmidt, 1974; Zbrodoff $\&$ Logan, 1986). For children, obligatory activation may occur as early as age 9 or 10 in addition (Miller \& Paredes, 1990), but it has not been found reliably in multiplication and in nonarithmetic tasks until age 12 or 13 (Hamann \& Ashcraft, 1985; Koshmider \& Ashcraft, 1991; LeFevre \& Bisanz, 1987; LeFevre et al., 1991). Third, adults require fewer cognitive resources to process simple arithmetic problems than children do (Kaye et al., 1989). These findings support the assumption that most adults, in comparison with children, have achieved automatic access to stored facts.

Comparisons made between children and adults, however, do not address the issue of whether automaticity is a source of individual differences within age groups. Most theorists assume that adults have achieved asymptotic performance on the retrieval of basic facts (Ashcraft, 1987; Siegler, 1988). The large individual differences that exist in arithmetic performance even among adults suggest, however, that not all adults have automatic retrieval processes (Widaman et al., 1992). For example, Geary and 
Widaman (1987) found that performance on a multidigit arithmetic test was related to speed of memory retrieval and speed of performing the carry procedure on a chronometric arithmetic task. These results suggest that variability among adults in multidigit arithmetic could, in part, be due to differences in the automaticity of fact retrieval.

In the present research, we examined the relation between individual differences in multidigit arithmetic performance and obligatory activation (automaticity) of basic facts. Because automatic access to basic facts is believed to enhance performance on more complex arithmetic tasks, we hypothesized that subjects who were more skilled on a complex arithmetic task would show larger effects of obligatory activation than would less skilled subjects.

\section{Evidence for Obligatory Activation of Arithmetic Facts}

Obligatory activation has been assessed in a variety of paradigms. One approach has been to measure crossoperation confusion errors in arithmetic tasks. Adults are slow to reject false statements like $3 \times 4=7$ in verification tasks (Winkelman \& Schmidt, 1974; Zbrodoff \& Logan, 1986) and they tend to make cross-operation errors in production tasks (Miller \& Paredes, 1990; Miller, Perlmutter, \& Keating, 1984). Children show evidence for cross-operation confusion in production tasks as early as Grade 3 (Miller \& Paredes, 1990), supporting the view that obligatory activation develops early (Koshmider \& Ashcraft, 1991). In multiplication, table-related confusion effects are found (Campbell, 1987b, 1991; Koshmider \& Ashcraft, 1991; Stazyk et al., 1982): Subjects are slow to reject problems like $3 \times 9=18$, supporting the hypothesis that activation of related information occurs without intention in a network representation.

Obligatory activation has also been studied in priming and interference tasks. The primary assumption behind these approaches is that, if obligatory activation occurs, then presentation of number pairs will result in the activation of related knowledge. Depending on the task, the activated knowledge may either facilitate processing or interfere with task completion.

Koshmider and Ashcraft (1991) recently presented evidence for obligatory activation of multiplication facts obtained in a priming task (see also Campbell, 1987b, 1991). Children in Grades 3, 5, and 7, as well as adults, saw a prime (e.g., 32) that was followed by a multiplication problem (e.g., $4 \times 8=32$ ). The prime was either related to the multiplication problem (e.g., 32), neutral (e.g., ".-."), or unrelated to the problem (e.g., 54). Subjects were faster at verifying problems preceded by a related prime than at verifying those preceded by a neutral prime. Unrelated primes slowed responses to the target problem relative to the neutral prime. These results suggest that activation of the answer node facilitated processing of the target problem, whereas an unrelated number resulted in inhibition of the target problem. Priming was found for all ages on problems with smaller operands, whereas only Grade 7 children and adults showed consistent priming on problems with large operands. Furthermore, priming was found with a short $(250-\mathrm{msec})$ delay between onset of the prime and onset of the problem, which is consistent with the assumption that activation spreads quickly in the number network. Priming and interference effects at longer delays were assumed to reflect conscious processing.

LeFevre and colleagues (LeFevre \& Bisanz, 1987; LeFevre et al., 1988; LeFevre et al., 1991; Thibodeau \& LeFevre, 1993) found evidence for obligatory activation in an interference task that did not involve arithmetic. Subjects were presented with a two-digit cue (e.g., 3+4) followed by a single digit. They were required to decide whether the single digit matched one of the numbers in the initial cue. Presentation of a two-digit cue is assumed to activate related digits in the network (e.g., the sum or product). When a target digit appeared that was related to the cue, subjects found it difficult to reject this target, even though it was not part of the digit cue. Thus, subjects were slower to decide that the sum (e.g., $3+4$ and 7) did not match a digit in the initial cue than to decide that an unrelated digit did not match (e.g., 3+4 and 9). Moreover, because sum targets produced interference only at short delays between presentation of the cue and the target (i.e., $120 \mathrm{msec}$ or less), activation in the network is presumably fast and automatic. At longer stimulus onset asynchronies (SOAs), subjects may use conscious processes to suppress activated digits that have not been presented, or activation of those digits may decay rapidly. Further, obligatory activation of the related arithmetic fact produced interference in conditions with and without a plus sign (i.e., $3+4$ and 34 ), suggesting that activation spreads from the presented digits, independent of the presence of the operation sign (LeFevre et al., 1988).

The number-matching task provides a strong test of the strength of associative connections in the network. Because associative strength is assessed in a context in which calculation of the sum is irrelevant, sum-based interference can clearly be attributed to obligatory activation, rather than to strategic processing. Moreover, the results of the study by LeFevre et al. (1991) suggest that retrieval in the context of an arithmetic task and obligatory activation of the sum are not necessarily equivalent. For children in the range of 8-11 years of age, LeFevre et al. did not find evidence for obligatory activation, even though children in that age range (and younger) are typically able to retrieve the sums of simple addition problems (Ashcraft \& Fierman, 1982; Hamann \& Ashcraft, 1985; Siegler \& Shrager, 1984). This result suggests that being able to retrieve some proportion of sums on an arithmetic task does not necessarily mean that the associative connections are strong enough to produce substantial activation in a nonarithmetic task. LeFevre et al. (1991) also found stronger evidence for associative connections based on number-line connections among children than among adults. Thus, the number-matching task is useful in as- 
sessing associative connections among numbers because it can be used to assess a variety of associative relations independent of intentional retrieval.

\section{Overview of Present Research}

The number-matching task developed by LeFevre et al. (1988) was used in two experiments to test the hypothesis that subjects who are skilled at multidigit computation would also show automatic activation of arithmetic facts. We hypothesized that subjects who perform well on a multidigit arithmetic test would show larger effects of obligatory activation than would less skilled subjects. This hypothesis is based on the assumption that automaticity of specific facts is an important component of performance on more complex arithmetic tasks. If all adults have achieved automatic access to stored facts, then obligatory activation will not vary with skill.

In both experiments, three types of problems were used as cues: plus-one cues had a one in the initial digit pair (e.g., $3+1)$; tie cues had identical digits in the initial pair (e.g., $3+3$ ); and standard cues had unequal digits, both larger than one (e.g., $3+2$ ). Tie and plus-one problems are learned earlier than standard problems (Groen \& Parkman, 1972; Siegler \& Shrager, 1984), and an advantage in solution latencies to these problems persists among adults (Miller et al., 1984). Three types of targets were included: (1) matching targets were the same as one of the digits in the cue (e.g., $3+1$ and 3); (2) sum targets were the sum of the cue digits (e.g., $3+1$ and 4); and (3) neutral targets were unrelated to the cue digits (e.g., $3+1$ and 6).

No previous research has directly addressed the question of whether accessibility of addition facts within the network is variable, although differential accessibility has been invoked as an explanation for problem-size effects (Ashcraft, 1992; Campbell \& Graham, 1985). Hence, one of our goals was to explore the relation between problem type and obligatory activation. On the basis of current literature and theory, two hypotheses were generated about how the type of cue might be related to automaticity. According to the general-accessibility hypothesis, automaticity is a property of the network as a whole, and evidence for equivalent levels of obligatory activation should therefore be found for all three cue types (standard, plusone, and ties). Alternatively, according to the specificaccessibility hypothesis, obligatory activation may vary with cue type, so that ties and plus-one cues may show more evidence for obligatory activation than standard cues. In general, according to network models of arithmetic acquisition, automaticity develops over time with extensive practice (e.g., Ashcraft, 1987; Campbell \& Graham, 1985; Siegler \& Jenkins, 1989; Siegler \& Shrager, 1984). Research has shown that tie problems are presented more frequently to children than are nontie problems by parents (Siegler \& Shrager, 1984) and that frequency of problem presentation in textbooks varies with factors such as problem size (Hamann \& Ashcraft, 1986). Thus, auto- maticity could vary with particular problems (specific accessibility) because different problems may receive different amounts of practice (see also Campbell, 1987a; Campbell \& Clark, 1989). Finally, individual differences may interact with accessibility. For example, less skilled subjects may show evidence for obligatory activation only on tie and plus-one problems. Thus, obligatory activation may vary with skill, with problem type, or with both variables.

\section{EXPERIMENT 1}

The number-matching task developed by LeFevre et al. (1988) was used to test for obligatory activation of simple addition facts. Subjects were divided into skilled and less skilled groups, on the basis of their performance on a multidigit arithmetic task. Finding individual differences in activation for these skill groups would support the hypotheses that (1) not all adults have achieved complete automaticity of basic facts and (2) individual differences in automaticity are related to performance on complex arithmetic tasks.

Six SOAs were used to assess obligatory activation: 40 , $60,80,120,140$, and $160 \mathrm{msec}$. A large number of relatively short SOAs was used, to facilitate finding the locus of interference effects. In order to assess the specific and general accessibility hypotheses, three cue types were presented: ties (e.g., $2+2$ ), plus-one cues (e.g., $3+1$ ), and standard cues (e.g., $3+2$ ).

\section{Method}

Subjects. Twenty-four introductory psychology students (12 males and 12 females) participated to partially fulfill a course requirement. The median age of the subjects was $21: 9$ (years:months), ranging from 18:11 to $34: 9$.

Materials. Each trial consisted of an initial digit cue (e.g., 2+3) and a subsequent digit target (e.g., 7). Excluded were combinations of digit cues and targets that might have elicited activation on the basis of some relation among the elements other than addition, such as multiplication (e.g., 2+4 =8; see Campbell \& Graham, 1985; Miller \& Paredes, 1990; Winkelman \& Schmidt, 1974), or number series relations (e.g., $2+4=6$; LeFevre \& Bisanz, 1986).

Four problem types were defined; they varied in the relation between the target and the digit cues and, consequently, also in the correct response (see Table 1). For both sum and neutral problems, the target did not match either number of the digit cue, and the correct response was "no." For sum problems, the target was equal to the sum of the digits in the cue. Targets for neutral problems were chosen from the set of sum targets.

LeFevre et al. (1988) found effects of the distance between the digits in the initial cue and the target. That is, more time was required to reject a target when it was relatively close to the digits in the initial cue (e.g., $5+3$ and 6$)$ than when the target was relatively far from those in the initial cue (e.g., $2+3$ and 8 ). Adults did not, however, show differential distance effects as a function of skill (LeFevre et al., 1991). In the present study, we were not interested in testing hypotheses about distance. Thus, to ensure that effects of sums were not confounded with effects of distance, we balanced sum and neutral items for average distances between cues and targets. The split between the target number and the digit cue was determined for each of the sum and neutral items by calculating 
Table 1

Problem Set From Experiments 1 and 2

\begin{tabular}{|c|c|c|c|c|c|c|}
\hline \multirow[b]{3}{*}{ Condition } & \multirow[b]{3}{*}{ Cues } & \multicolumn{4}{|c|}{ Targets } & \multirow[b]{3}{*}{ Cues } \\
\hline & & \multicolumn{2}{|c|}{ Nonmatching } & \multicolumn{2}{|c|}{ Matching } & \\
\hline & & Sum & Neutral & Cue & Target & \\
\hline \multirow[t]{10}{*}{ Standard } & $2+3$ & 5 & 8 & 2 & 5 & $7+5$ \\
\hline & $3+2$ & 5 & 7 & 3 & 5 & $5+8$ \\
\hline & $2+5$ & 7 & 9 & 5 & 7 & $3+7$ \\
\hline & $5+2$ & 7 & 9 & 2 & 7 & $9+7$ \\
\hline & $6+2$ & 8 & 5 & 2 & 8 & $5+8$ \\
\hline & $5+3$ & 8 & 6 & 5 & 8 & $9+8$ \\
\hline & $4+3$ & 7 & 9 & 4 & 7 & $7+9$ \\
\hline & $3+5$ & 8 & 6 & 3 & 8 & $8+4$ \\
\hline & $6+3$ & 9 & 7 & 3 & 9 & $9+1$ \\
\hline & $5+4$ & 9 & 7 & 4 & 9 & $9+6$ \\
\hline \multirow[t]{6}{*}{ Tie } & $2+2$ & 4 & 7 & 2 & 9 & $3+9$ \\
\hline & $2+2$ & 4 & 8 & 2 & 6 & $6+8$ \\
\hline & $3+3$ & 6 & 5 & 3 & 6 & $6+7$ \\
\hline & $3+3$ & 6 & 8 & 3 & 6 & $6+9$ \\
\hline & $4+4$ & 8 & 6 & 4 & 7 & $7+5$ \\
\hline & $4+4$ & 8 & 5 & 4 & 9 & $5+9$ \\
\hline \multirow[t]{6}{*}{ Plus-one } & $3+1$ & 4 & 6 & 3 & 6 & $6+4$ \\
\hline & $1+3$ & 4 & 6 & 1 & 6 & $9+6$ \\
\hline & $7+1$ & 8 & 4 & 1 & 4 & $3+4$ \\
\hline & $1+7$ & 8 & 5 & 7 & 5 & $5+7$ \\
\hline & $1+8$ & 9 & 5 & 8 & 5 & $6+5$ \\
\hline & $8+1$ & 9 & 5 & 1 & 5 & $3+5$ \\
\hline
\end{tabular}

Note-Cues in the leftmost column were used for sum, neutral, and cuecontrol items. Cues in the rightmost column were used for target-control items.

the average difference between each number in the digit cue and the target. For example, the average split for the problem " $2+3 \quad 8$ " is 5.5 . The resulting mean values of split did not differ significantly between sum $(3.5)$ and neutral $(3.8)$ problems $[t(22)<1]$.

For the cue-control and target-control problems, the target matched a number of the digit cue, and the correct response was "yes." Cue-control problems consisted of the same digit cues as those used for the sum and neutral problems. For half the cue-control problems, the target matched the digit on the right side of the cue, and in the remaining problems, the target matched the digit on the left side of the cue. Target-control items were constructed to ensure that the targets for problems with "yes" responses covered the same range as those for problems with "no" responses. Of particular concern was the inclusion of problems with large target values that would balance the relatively small values found in the set of cue-control targets.

The sum, neutral, and cue-control problems were presented in three cue conditions in which the relation between the digit cue $(m+n)$ was varied (see Table 1). For standard cues, the digit cues were of the form $m>1, n>1$ and $m \neq n$ (e.g., $2+7)$; tie cues comprised identical digits ( $m=n$; e.g., $2+2)$; plus-one cues were of the form $m=1$ or $n=1$ (e.g., $3+1$ or $1+3$ ).

Two lists of the stimuli were used, one the reverse order of the other. Within each list, all problems appeared at each of three SOAs for a total of 264 trials per list. Each list was presented in one of two sets with variable SOAs between number cue and target. The SOAs between digit cue and target in Set $A$ were 40,120 , and $160 \mathrm{msec}$; in Set B, the SOAs were 60,80 , and $140 \mathrm{msec}$. The ordering of stimuli within lists was random, with the following six constraints: (1) the same problem type did not appear more than two times in succession; (2) the same target digit did not appear more than two times in succession; (3) the same response was not correct more than three times in succession; (4) the same digit did not appear more than three times in succession; (5) the same digit did not appear in the same position more than two times in succes- sion; and (6) problems did not appear at the same SOA more than two times in succession.

Each subject completed both Set $\mathrm{A}$ and Set B, with a different order of the stimuli presented for each set. The order of set presentation (A or B first) and list order was counterbalanced with sex across subjects.

Arithmetic skill was assessed with an arithmetic test involving multidigit addition, subtraction, and multiplication problems (French, Ekstrom, \& Price, 1963). This test includes four pages of problems: two pages of three-term addition problems (120 total), and two pages of combined two-term subtraction and multiplication problems ( 60 of each type). Subjects were given $2 \mathrm{~min}$ per page to solve as many problems as possible. They were instructed to solve the problems as quickly as possible without sacrificing accuracy. Problems of each type (i.e., addition, subtraction, and multiplication) were preceded by 10 practice problems of the same type.

The subjects also completed a mathematics background and interest questionnaire that served as a filler task between the two problem sets. The data from the questionnaire were not of interest for the present purposes and are not discussed further.

Apparatus. Items were presented on a Samsung Model SM 125FA7 monochrome monitor controlled by an IBM 80286type microcomputer. Response collection and timing were done with a Digitek Developments I/O board; timing was accurate to the nearest millisecond. SOAs were precisely controlled by linking presentation of stimuli to the refresh rate of the video monitor (20msec cycles). Thus, the initial cue was presented for the SOA minus $20 \mathrm{msec}$; then the screen was turned off for $20 \mathrm{msec}$, and the target was written to the screen. At the beginning of the next video cycle, the screen was turned back on to display the target. Thus, the interstimulus interval at each SOA was $20 \mathrm{msec}$.

The subjects responded to targets by pressing an appropriate microswitch key on a two-key response panel. They were instructed to place the index finger of the preferred hand between the two keys and to return the finger to that position after each response.

Procedure. Each trial began with the presentation of the prompt, "*", which remained on the screen until the subject pressed the right-hand key to initiate the trial. After a 600 -msec delay, a digit cue was presented. Following a variable SOA $(40,120$, or $160 \mathrm{msec}$ in Set $\mathrm{A} ; 60,80$, or $140 \mathrm{msec}$ in Set B), the number cue disappeared and the target digit was presented one line below the position of the number cue, centered under the location of the plus sign. The target number remained on the screen until the subject responded "yes" or "no" by pressing the appropriate key, or for a maximum of 5 sec. Latency (in milliseconds) and accuracy were recorded, and subjects received auditory feedback regarding the accuracy of each response: An ascending series of four tones followed a correct response, and a short buzzer sound followed an incorrect response.

Before the experimental trials, the subjects were given 10 practice trials with auditory feedback. The practice trials included items that were similar to each of the four experimental problem types. The subjects were instructed to respond as quickly as possible without sacrificing accuracy. If a subject made errors on more than 2 of the 10 practice trials, or still felt uncomfortable with the response procedure, the practice set was repeated. The practice set was repeated with two subjects.

Sets $A$ and $B$ of the digit-matching task each required approximately $10 \mathrm{~min}$ to complete. The mathematics background and interest questionnaire was administered between the two sets. The subjects completed the arithmetic fluency test after finishing the second set of experimental trials. Each experimental session lasted approximately $45 \mathrm{~min}$.

\section{Results}

A median split on total score on the math fluency test was used to divide subjects into two skill groups. Fortui- 
tously, six males and six females fell into each skill group. To check the legitimacy of the skill division, the fluency scores were analyzed in a 2 (skill) $\times 2$ (sex) analysis of variance (ANOVA). Skilled subjects scored significantly better than less skilled subjects (112 vs. 75 correct out of a possible 240$)[F(1,20)=36.88, p<.001]$. There was no main effect of sex, but the sex $\times$ skill interaction approached significance $[F(1,20)=3.06, p=.095]$. Less skilled males and females performed very similarly (74 vs. 76), but skilled males had higher average scores than did skilled females (122 vs. 102).

Mean latencies ${ }^{1}$ (correct responses only) and percentage of errors were analyzed in separate ANOVAs that included two between-subjects factors, 2 (skill: low, high) $\times 2$ (sex: male, female), and three repeated measures factors, 3 (cue: standard, tie, plus-one) $\times 2$ (target: sum, neutral) $\times 6$ (SOA: $40,60,80,120,140,160 \mathrm{msec}$ ). Mean latencies and percentage errors are shown in Table 2.

Latencies. Latencies declined with SOA $[F(5,100)=$ $\left.8.47, M S_{\mathrm{e}}=43,062, p<.001\right]$. Both the linear and quadratic components of the effect were significant $[F \mathrm{~s}(1,100)$ $=28.2$ and 8.37, respectively, $p$ s $<.05]$. Comparisons between means using the Tukey HSD procedure with $p<$ .05 indicated that only the $40-\mathrm{msec}$ SOA (938 msec) differed significantly from any of the others $(858,834,832$, 789 , and $822 \mathrm{msec}$, respectively). At $40 \mathrm{msec}$, subjects are still processing the cue when the target appears, resulting in longer latencies (LeFevre et al., 1988).

Sum targets were responded to more slowly than neutral targets (858 vs. $833 \mathrm{msec})\left[F(1,20)=11.48, M S_{\mathrm{e}}=\right.$ $11,279, p<.01$, replicating the interference effect ob- served by LeFevre and colleagues (LeFevre et al., 1988; LeFevre et al., 1991). The interaction between target type and SOA approached significance $[F(1,100)=1.91$, $\left.M S_{\mathrm{e}}=11,700, p=.095\right]$. The only significant differences between sum and neutral targets were at 40 and $60 \mathrm{msec}$ (differences of 38 and $68 \mathrm{msec}$, respectively) $\left[F \mathrm{~S}(1,120)=4.53\right.$ and 14.09 , respectively, $M S_{\mathrm{e}}=$ $11,630]$. These findings replicate those of LeFevre et al. (1988; Experiment 1) and are consistent with the notion that the presentation of digit cues results in the activation of associated information in the stored network of arithmetic facts at short SOAs. At longer SOAs, this information either is suppressed or decays and no longer influences number-matching performance.

Skill-related differences in obligatory activation address the issue of whether there is variability among adults in automaticity of access to basic facts. Hence, effects of skill were of particular interest. Skill interacted with target type $\left[F(1,20)=4.54, M S_{\mathrm{e}}=11,279, p<.05\right]$. Less skilled subjects did not show an interference effect for sum as opposed to neutral targets ( $881 \mathrm{vs.} 872 \mathrm{msec}$ ). In contrast, skilled subjects were significantly slower to reject sum as opposed to neutral targets ( $834 \mathrm{vs} .795 \mathrm{msec}$ ) $\left[F(1,20)=15.23, M S_{\mathrm{e}}=11,279\right]$. There was also a significant three-way interaction of skill, target, and SOA $\left[F(5,100)=3.19, M S_{\mathrm{e}}=11,700, p<.05\right]$, as shown in Figure 1. The interaction of skill and target was significant at $40 \mathrm{msec}\left[F(1,100)=15.44, M S_{\mathrm{e}}=11,700\right.$, $p<.01$ ], indicating that skilled subjects showed larger effects of obligatory activation than did less skilled subjects. Tests of simple effects indicated that interference effects were significant for skilled subjects at the 40 - and

Table 2

Mean Latencies (in Milliseconds) and Percentage of Errors in Experiment 1

\begin{tabular}{|c|c|c|c|c|c|c|c|c|c|c|c|c|}
\hline \multirow[b]{3}{*}{ Condition } & \multicolumn{12}{|c|}{ SOA } \\
\hline & \multicolumn{2}{|c|}{40} & \multicolumn{2}{|c|}{60} & \multicolumn{2}{|c|}{80} & \multicolumn{2}{|c|}{120} & \multicolumn{2}{|c|}{140} & \multicolumn{2}{|c|}{160} \\
\hline & $M$ & $\% E$ & $\bar{M}$ & $\% E$ & $M$ & $\% E$ & $M$ & $\% E$ & $M$ & $\% E$ & $M$ & $\% E$ \\
\hline \multicolumn{13}{|c|}{ Less-Skilled Subjects } \\
\hline \multicolumn{13}{|l|}{ Standard } \\
\hline Sum & 945 & 3.3 & 869 & 4.2 & 812 & 5.8 & 904 & 4.2 & 809 & 8.3 & 888 & 4.2 \\
\hline Neutral & 968 & 4.2 & 815 & 6.7 & 817 & 3.3 & 868 & 3.3 & 807 & 1.7 & 841 & 4.2 \\
\hline \multicolumn{13}{|l|}{ Tie } \\
\hline Sum & 1016 & 16.7 & 955 & 18.0 & 919 & 19.5 & 928 & 12.6 & 847 & 12.7 & 927 & 11.2 \\
\hline Neutral & 1032 & 24.9 & 898 & 16.8 & 865 & 12.5 & 923 & 12.7 & 829 & 9.7 & 975 & 9.7 \\
\hline \multicolumn{13}{|l|}{ Plus-one } \\
\hline Sum & 916 & 11.2 & 862 & 2.8 & 823 & 4.2 & 863 & 2.8 & 760 & 2.8 & 816 & 0.0 \\
\hline Neutral & 976 & 5.7 & 836 & 7.0 & 817 & 0.0 & 774 & 4.2 & 830 & 1.4 & 823 & 0.0 \\
\hline \multicolumn{13}{|c|}{ Skilled Subjects } \\
\hline \multicolumn{13}{|l|}{ Standard } \\
\hline Sum & 942 & 5.8 & 865 & 5.8 & 811 & 4.2 & 780 & 3.3 & 817 & 1.7 & 800 & 3.3 \\
\hline Neutral & 837 & 3.3 & 804 & 2.5 & 814 & 0.8 & 797 & 1.7 & 774 & 0.8 & 777 & 1.7 \\
\hline \multicolumn{13}{|l|}{ Tie } \\
\hline Sum & 993 & 18.1 & 965 & 14.0 & 876 & 5.7 & 799 & 11.2 & 776 & 2.8 & 769 & 7.0 \\
\hline Neutral & 913 & 16.7 & 827 & 16.7 & 898 & 5.6 & 792 & 2.8 & 765 & 1.4 & 777 & 0.0 \\
\hline \multicolumn{13}{|l|}{ Plus-one } \\
\hline Sum & 929 & 5.5 & 837 & 1.4 & 782 & 1.4 & 789 & 2.8 & 745 & 4.2 & 749 & 0.0 \\
\hline Neutral & 787 & 8.4 & 767 & 1.4 & 776 & 4.2 & 764 & 1.4 & 713 & 4.2 & 726 & 2.8 \\
\hline
\end{tabular}

Note-SOA, stimulus onset asynchrony. 


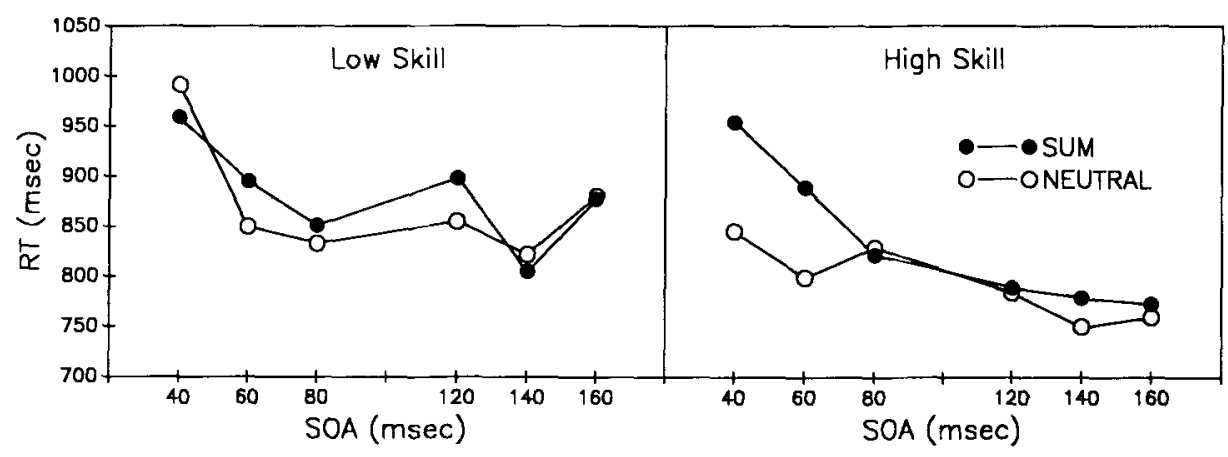

Figure 1. Latencies on sum and neutral problems by stimulus onset asynchrony in Experiment 1 for skilled and less skilled subjects.

60 -msec SOAs $\left[F_{\mathrm{s}}(1,120)=18.4\right.$ and $12.4, M S_{\mathrm{e}}=$ $11,630]$. In contrast, for less skilled subjects, there were no significant differences between latencies for sum and neutral targets. These findings support the hypothesis that automaticity of access to arithmetic facts varies among adults and suggest that one source of individual differences in the solution of complex arithmetic problems may be the accessibility of the simple arithmetic facts.

Effects of cue type address the issue of whether accessibility is specific to certain facts or is a general property of the network. Latencies to ties $(856 \mathrm{msec})$ were significantly slower than latencies to plus-one items $(811 \mathrm{msec}$; Tukey HSD, $p<.05$ ), but latencies for standard cues $(840 \mathrm{msec})$ were not significantly different from either of the other cue types $\left[F(2,40)=18.35, M S_{\mathrm{e}}=22,475\right.$, $p<.001]$. However, the effect of cue did not interact with target type (i.e., sum vs. neutral), suggesting that the increased latency for ties reflected the processing of the initial cue rather than the processing of the target. The interaction of skill, cue type, and target type was also not significant: Less skilled subjects did not show evidence for interference on any of the three cue types, whereas interference was reasonably consistent across cue types for skilled subjects, averaging $35 \mathrm{msec}$ for standard, $34 \mathrm{msec}$ for tie, and $50 \mathrm{msec}$ for plus-one cues across SOAs. ${ }^{2}$ In outline, these findings seem most consistent with the general accessibility view of the arithmetic network.

Inspection of the data in Table 2, however, suggest that interference did vary somewhat across cue types at the shortest SOAs. As shown in Figure 2, for skilled subjects, interference was greatest at $40 \mathrm{msec}$ for standard and plusone cues $\left[F_{\mathrm{s}}(1,200)>6.59, M S_{\mathrm{e}}=10,028, p \mathrm{~s}<.01\right]$, whereas for ties, the effect approached significance $[F(1,200)=3.83]$. At $60 \mathrm{msec}$, the interference effect was significant only for ties $[F(1,200)=11.39]$, suggesting that the time course of interference for ties may be slightly slower but may persist longer. None of the interference effects were significant for less skilled subjects. However, tests of the interaction between skill and problem type (sum vs. neutral) for each cue type were significant only for standard and plus-one cues at $40 \mathrm{msec}$
$[F \mathrm{~s}(1,200)>4.90, p s<.05]$. These comparisons suggest that the differences between skilled and less skilled subjects are smallest on tie cues and provide limited support for the specific accessibility view. For less skilled subjects, the moderate interference observed on ties at $60 \mathrm{msec}$ also occurs at $80 \mathrm{msec}$, suggesting again that activation of ties is more persistent than that of other cue types.

Analysis of errors. Errors varied significantly with cue type $\left[F(2,40)=43.13, M S_{\mathrm{e}}=58.8, p<.01\right]$. Subjects made substantially more errors on ties $(11.6 \%)$ than on standard $(3.7 \%)$ or plus-one cues $(3.3 \%$; Tukey HSD, $p<.05)$. Cue type also interacted with skill $[F(2,40)=$ 4.76, $\left.M S_{\mathrm{e}}=147.0, p<.05\right]$. Less skilled subjects made more errors than skilled subjects on tie items (14.8 vs. $8.5 \%)\left[F(1,60)=11.4, M S_{\mathrm{e}}=24.6, p<.05\right]$, but the two groups did not differ on standard $(4.4 \%$ vs. $2.9 \%)$ or plus-one items $(3.5 \%$ vs. $3.2 \%)$.

Errors decreased with increases in SOA $[F(5,100)=$ $\left.6.25, M S_{\mathrm{e}}=147.0, p<.01\right]$, and SOA interacted with cue type $\left[F(10,200)=3.70, M S_{\mathrm{e}}=162.7, p<.05\right]$ (see Table 3). For standard items, there was no change in errors with SOA, whereas plus-one items showed a significant linear decline $[F(1,300)=7.03]$, and tie items showed both linear and quadratic trends $\left[F_{\mathrm{s}}(1,300)=\right.$ 53.74 and $4.06, M S_{\mathrm{e}}=103$ ]. Subjects made substantially

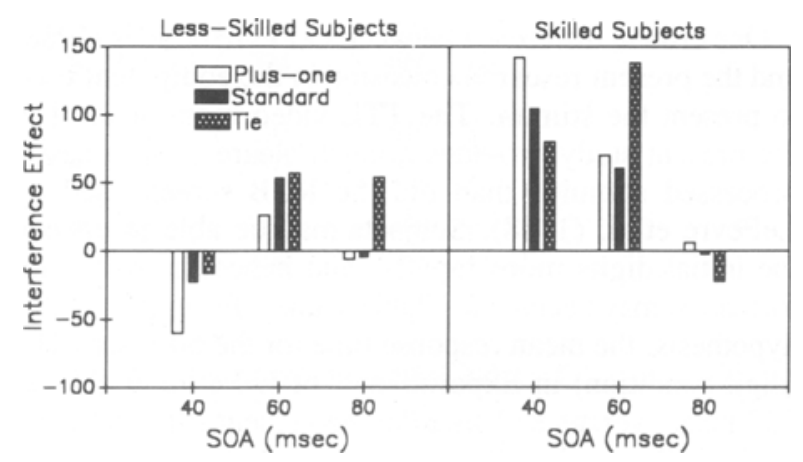

Figure 2. Interference effects (difference between sum and neutral latencies) for skilled and less skilled subjects by cue type and stimulus onset asynchrony in Experiment 1. 
Table 3

Mean Latencies (in Milliseconds) and Percentage of Errors as a Function of Cue Type and Stimulus Onset Asynchrony in Experiment 1

\begin{tabular}{|c|c|c|c|c|c|c|c|c|c|c|c|c|}
\hline \multirow[b]{3}{*}{ Condition } & \multicolumn{12}{|c|}{ SOA } \\
\hline & \multicolumn{2}{|c|}{40} & \multicolumn{2}{|c|}{60} & \multicolumn{2}{|c|}{80} & \multicolumn{2}{|c|}{120} & \multicolumn{2}{|c|}{140} & \multicolumn{2}{|c|}{160} \\
\hline & $M$ & $\% E$ & $M$ & $\% E$ & $M$ & $\% E$ & $M$ & $\% E$ & $M$ & $\% E$ & $M$ & $\% E$ \\
\hline Standard & 922 & 4.2 & 838 & 4.8 & 813 & 3.5 & 837 & 3.1 & 801 & 3.1 & 827 & 3.3 \\
\hline Plus-one & 902 & 7.7 & 825 & 3.2 & 799 & 2.4 & 797 & 2.8 & 762 & 3.2 & 779 & 0.7 \\
\hline Ties & 988 & 19.1 & 911 & 16.4 & 889 & 10.8 & 860 & 9.8 & 804 & 6.7 & 862 & 7.0 \\
\hline
\end{tabular}

more errors on ties than on the other two item types at the four shortest SOAs, but by 140 and $160 \mathrm{msec}$, error rates did not differ significantly (Tukey HSD, $p<.05$, $\left.M S_{\mathrm{e}}=162.7\right)$. Evidently, ties generated more interference at encoding than did standard or plus-one items. Encoding the same number twice may have activated that number very strongly, making it difficult to reject any related digit. Alternatively, the "double-activation" of one set of associations for tie problems versus the "single-activation" of two sets of associations for nontie problems may have resulted in greater interference for tie problems because of stronger levels of activation within the network.

\section{Discussion}

The results of this study provide further evidence that sums are activated without intention on presentation of a digit cue (LeFevre et al., 1988; LeFevre et al., 1991). The interference effect was larger for skilled than for less skilled subjects, supporting the hypothesis that accessibility of arithmetic facts may be a factor in individual differences in the solution of complex problems.

The results of this study replicate those found by LeFevre et al. (1988) and extend the interference effect to a wider range of problems. There were, however, some differences between the results reported by LeFevre et al. and those of the present research. LeFevre et al. included SOAs of $60,120,180,240$, and $480 \mathrm{msec}$ and observed significant interference only at the $120-\mathrm{msec}$ SOA. The general claim, that interference is generated rapidly and declines at longer SOAs, still holds. A question remains, however: Why did interference occur at substantially shorter SOAs in the present study?

One critical difference between LeFevre et al.'s (1988) and the present research consisted in the equipment used to present the stimuli. The TTL video monitor used in the present study provides a much clearer, more easily processed stimulus than did the RGB screen used by LeFevre et al. (1988). Subjects may be able to encode the initial digits more rapidly, and hence, activated information may become available sooner. In support of this hypothesis, the mean response time for the 60 -msec SOA (digit condition) in Experiment 1 of LeFevre et al. was $887 \mathrm{msec}$, versus $832 \mathrm{msec}$ in the present study (ties excluded). Research in the word-recognition literature supports the view that stimulus quality affects the speed of encoding (Stanners, Jastrembski, \& Westbrook, 1975).
A second difference is that LeFevre et al. (1988) did not assess individual differences. When skill is ignored in this study, the largest difference occurs at the 60 -msec SOA. In combination with the encoding difference discussed above (of approximately $55 \mathrm{msec}$ ), it is perhaps not surprising that LeFevre et al. found the largest difference between sum and neutral items at $120 \mathrm{msec}$ (in Experiment 1, comparable [plus] condition). Thus, the results of the present study are only superficially different from those of LeFevre et al. (1988).

In conclusion, the results of this experiment are consistent with the view that skilled subjects are more likely to experience obligatory activation of simple addition facts than are less skilled subjects. For less skilled subjects, interference effects were consistently moderate and not statistically significant. The pattern of activation for ties suggested that some tie activation may have occurred for less skilled subjects. LeFevre et al. (1991) found that less skilled subjects did show evidence of obligatory activation, but at a longer SOA than did skilled subjects. LeFevre et al. (1991) used a different item set (not differentiated into standard, plus-one, and tie cues) and included longer SOAs (i.e., $60,80,120,200$, and $500 \mathrm{msec}$ ). The use only of short SOAs in the present experiment may have caused a bias against finding effects of obligatory activation among less skilled subjects. Thus, longer SOAs were used in Experiment 2, although the critical short SOAs ( 40 and $60 \mathrm{msec}$ ) were retained.

The results of Experiment 1 were most consistent with the general accessibility hypothesis, in that obligatory activation occurred for skilled subjects on all cue types (i.e., standard, plus-one, and tie). There was some suggestion, however, that activation of ties persisted longer. Furthermore, the high error rates on ties may indicate strong obligatory activation. Because cue types had not been compared in any other study, it was important to replicate these findings. Slow latencies and relatively large error rates on tie items may have masked differential interference effects for ties as opposed to nonties. Thus, Experiment 2 provided a replication of cue effects as well as an extended range of SOAs.

\section{EXPERIMENT 2}

Experiment 2 differed from Experiment 1 in that (1) no plus sign was given between the initial digits, and (2) the 
SOAs were $40,60,120,160,200$, and $400 \mathrm{msec}$. Longer SOAs were included to provide a closer replication of those used by LeFevre and colleagues (LeFevre et al., 1988; LeFevre et al., 1991). Furthermore, LeFevre et al. (1991) found evidence for obligatory activation among less skilled subjects at a longer SOA than that for skilled subjects, with different items and a different set of SOAs $(60,80,120,200$, and $500 \mathrm{msec})$. Thus, longer SOAs were included in this experiment so that we could assess whether obligatory activation might be found for less skilled subjects at longer SOAs than those for skilled subjects.

In Experiment 2, the plus sign was omitted between the initial digits in order to provide a strong test of the hypothesis that obligatory activation occurs without intention in this task. LeFevre et al. (1988) also included a blank condition. Interference was found for both plus and blank conditions in that study, suggesting that obligatory activation is driven primarily by the digits in the cue and less strongly by the operation sign. This is consistent with the view that addition and multiplication facts are stored in a single memory network (Geary, Widaman, \& Little, 1986). Alternatively, effects of the plus sign may be limited to situations in which there is an intention to retrieve. LeFevre et al. (1988) did observe some differences between plus and blank conditions however; in the blank condition, significant interference was found at both 60 and 120-msec SOAs, whereas interference was found only at $120 \mathrm{msec}$ in the plus condition. That difference was ascribed to encoding: One less symbol needs to be encoded in the blank (as opposed to the plus) condition. Because encoding was somewhat faster in Experiment 1 than in LeFevre et al. (1988), the pattern of interference effects may vary in plus versus blank presentation.

\section{Method}

Materials and Procedure. The materials and procedure were identical to those of Experiment 1, except for the SOAs. The SOAs used in Set A were 40, 120, and $200 \mathrm{msec}$; the SOAs used in Set B were 60,160 , and $400 \mathrm{msec}$.

Subjects. A total of 31 introductory psychology students ( 15 males and 16 females) participated to partially fulfill a course requirement. As in Experiment 1, skilled and less skilled groups with equal numbers of males and females were created; hence, the data were analyzed for only 24 of these subjects. Of the first 16 subjects who participated, only 4 had fluency scores that could be considered skilled (using the cutoffs from Experiment 1). Of the next 15 subjects who participated in the experiment, 8 were classified as skilled. From the remaining group of 19 subjects, the 12 subjects with the lowest scores were selected, with the constraint that half were males and half were females. Median age of these 24 subjects was 20:3 (years:months), ranging from 18:3 to $31: 1$.

\section{Results}

Arithmetic fluency scores were analyzed in a 2 (skill) $\times 2$ (sex) ANOVA. Skilled subjects had higher fluency scores than did less skilled subjects (114 vs. 74) $[F(1,20)=52.44]$; males scored higher than females $(101$ vs. 87$)[F(1,20)=8.31, p<.01]$; and the interaction was significant $[F(1,20)=5.49, p<.05]$. As in Experiment 1 , skilled males scored higher than skilled females (126 vs. 101), whereas fluency scores did not vary by sex for less skilled subjects ( 76 vs. 73 ). When fluency scores from both experiments were analyzed together, main effects of skill and sex, as well as the skill $\times$ sex interaction were significant. There was, however, no effect of experiment, indicating that the skill groups were similar in the two studies.

As in Experiment 1, mean latencies and percentage errors were analyzed in separate mixed ANOVAs. The data from these analyses are presented in Table 4.

Table 4

Mean Latencies (in Milliseconds) and Percentage Errors in Experiment 2

\begin{tabular}{|c|c|c|c|c|c|c|c|c|c|c|c|c|}
\hline \multirow[b]{3}{*}{ Condition } & \multicolumn{12}{|c|}{ SOA } \\
\hline & \multicolumn{2}{|c|}{40} & \multicolumn{2}{|c|}{60} & \multicolumn{2}{|c|}{120} & \multicolumn{2}{|c|}{160} & \multicolumn{2}{|c|}{200} & \multicolumn{2}{|c|}{400} \\
\hline & $M$ & $\% E$ & $M$ & $\% E$ & $M$ & $\% E$ & $M$ & $\% E$ & $M$ & $\% E$ & $M$ & $\% E$ \\
\hline \multicolumn{13}{|c|}{ Less-Skilled Subjects } \\
\hline \multicolumn{13}{|l|}{ Standard } \\
\hline Sum & 854 & 9.2 & 888 & 2.5 & 765 & 0.8 & 786 & 5.8 & 752 & 4.2 & 723 & 0.8 \\
\hline Neutral & 816 & 8.3 & 822 & 3.3 & 740 & 0.8 & 741 & 1.7 & 724 & 2.5 & 666 & 1.7 \\
\hline \multicolumn{13}{|l|}{ Ties } \\
\hline Sum & 861 & 25.1 & 856 & 16.7 & 796 & 9.8 & 735 & 7.1 & 693 & 7.0 & 619 & 8.3 \\
\hline Neutral & 878 & 20.8 & 833 & 16.7 & 768 & 8.4 & 703 & 7.0 & 703 & 1.4 & 663 & 2.7 \\
\hline \multicolumn{13}{|l|}{ Plus-one } \\
\hline Sum & 843 & 2.8 & 804 & 5.7 & 684 & 0.0 & 715 & 1.4 & 739 & 0.0 & 678 & 1.4 \\
\hline Neutral & 810 & 5.7 & 790 & 5.6 & 732 & 2.8 & 706 & 1.4 & 699 & 0.0 & 678 & 4.2 \\
\hline \multicolumn{13}{|c|}{ Skilled Subjects } \\
\hline \multicolumn{13}{|l|}{ Standard } \\
\hline Sum & 918 & 19.2 & 822 & 7.5 & 784 & 7.5 & 742 & 5.8 & 763 & 5.0 & 706 & 5.0 \\
\hline Neutral & 864 & 12.5 & 814 & 10.8 & 768 & 5.0 & 728 & 2.5 & 731 & 3.3 & 703 & 1.7 \\
\hline \multicolumn{13}{|l|}{ Ties } \\
\hline Sum & 926 & 44.5 & 958 & 22.2 & 851 & 12.5 & 753 & 7.0 & 792 & 1.4 & 695 & 2.8 \\
\hline Neutral & 1014 & 33.5 & 849 & 25.1 & 891 & 13.9 & 768 & 8.4 & 801 & 8.4 & 733 & 4.2 \\
\hline \multicolumn{13}{|l|}{ Plus-one } \\
\hline Sum & 872 & 5.6 & 866 & 8.3 & 754 & 5.6 & 724 & 4.2 & 762 & 1.4 & 689 & 2.8 \\
\hline Neutral & 894 & 15.2 & 790 & 12.7 & 772 & 4.2 & 757 & 4.2 & 771 & 6.9 & 665 & 1.4 \\
\hline
\end{tabular}


Table 5

Mean Latencies (in Milliseconds) and Percentage of Errors as a Function of Cue Type and Stimulus Onset Asynchrony in Experiment 2

\begin{tabular}{|c|c|c|c|c|c|c|c|c|c|c|c|c|}
\hline \multirow[b]{3}{*}{ Condition } & \multicolumn{12}{|c|}{ SOA } \\
\hline & \multicolumn{2}{|c|}{40} & \multicolumn{2}{|c|}{60} & \multicolumn{2}{|c|}{120} & \multicolumn{2}{|c|}{160} & \multicolumn{2}{|c|}{200} & \multicolumn{2}{|c|}{400} \\
\hline & $M$ & $\% E$ & $M$ & $\% E$ & $M$ & $\% E$ & $M$ & $\% E$ & $M$ & $\% E$ & $M$ & $\% E$ \\
\hline Standard & 863 & 12.3 & 836 & 6.0 & 764 & 3.5 & 739 & 4.0 & 742 & 3.8 & 700 & 2.3 \\
\hline Plus-one & 854 & 7.3 & 813 & 8.1 & 735 & 3.2 & 725 & 2.8 & 743 & 2.1 & 678 & 2.4 \\
\hline Ties & 920 & 31.0 & 874 & 20.2 & 826 & 11.2 & 740 & 7.4 & 747 & 4.6 & 677 & 4.5 \\
\hline
\end{tabular}

Errors. As in Experiment 1, subjects made more errors in response to tie $(13.1 \%)$ than to standard $(5.3 \%)$ or plusone cues $(4.3 \%)\left[F(2,40)=34.57, M S_{\mathrm{e}}=194.2, p<\right.$ $.001]$; errors decreased with increases in SOA $[F(5,100)$ $\left.=21.18, M S_{\mathrm{e}}=202.5, p<.001\right]$; and these two factors interacted $\left[F(10,200)=8.89, M S_{\mathrm{e}}=111.6, p<\right.$ $.01]$ (see Table 5). Subjects made more errors in response to tie than to standard or plus-one cues at 40,60 , and 120 msec only (Tukey HSD, $p<.05$ ).

Target type interacted with cue type $[F(2,40)=3.42$, $\left.M S_{\mathrm{e}}=85.3, p<.05\right]$. More errors were made in response to sum than to neutral targets for standard $(6.1 \%$ vs. $4.5 \%)$ and tie targets $(13.7 \%$ vs. $12.6 \%)$, but the reverse was true for plus-one targets (3.3\% vs. $5.4 \%)$ : Tests of simple effects indicated that none of these differences between sum and neutral items were statistically significant. Skill interacted with SOA $\left[F(5,100)=2.37, M S_{\mathrm{e}}=\right.$ 202.5, $p<.05$ ]: Tests of simple effects indicated that skilled subjects made more errors than did less skilled subjects at the 40-msec SOA $(19.8 \%$ vs. $12.0 \%)[F(1,120)=$ $\left.10.03, M S_{\mathrm{e}}=343.2, p<.05\right]$; differences at the 60msec $(14.5 \%$ vs. $8.5 \%)$ and 120 -msec SOAs $(8.2 \%$ vs. $3.8 \%$ ) were in the same direction, but not statistically significant. At the three longer SOAs, all error percentages were less than $6 \%$ and skilled and less skilled subjects did not differ. ${ }^{3}$ Thus, skilled subjects made more errors than did less skilled subjects, especially at the shortest SOA. This result compromises interpretation of the latency effects at the 40-msec SOA.

Latencies. As in Experiment 1, sum targets were rejected more slowly than neutral targets ( $782 \mathrm{vs} .772 \mathrm{msec}$ ) $\left[F(1,20)=4.73, M S_{\mathrm{e}}=5,129, p<.05\right]$, supporting the hypothesis that obligatory activation occurs in the number-matching task even when the plus sign is omitted. Latencies varied with SOA $\left[F(5,100)=17.76, M S_{\mathrm{e}}=\right.$ $41,486, p<.05]$; and the interaction of target type and SOA approached significance $\left[F(5,100)=2.14, M S_{\mathrm{e}}=\right.$ $6,723, p=.066$ ]. Comparisons made between sum and neutral items at each SOA indicated that the only significant difference occurred at the 60-msec SOA (difference of $50 \mathrm{msec})\left[F(1,120)=13.52, M S_{\mathrm{e}}=6,457, p<.01\right]$. Thus, as in Experiment 1, the largest difference between sum and neutral targets occurred at a short SOA.

Skill differences were of particular interest, as in Experiment 1 . The interaction between target type and skill was not significant in the overall analysis $[F(1,20)=$ $2.07, p=.17]$, or at any of the SOAs. At the $60-\mathrm{msec}$ SOA, however, the pattern of results was the same as in Experiment 1 (see Figure 3), with the skilled subjects showing a larger interference effect than the less skilled subjects did. Tests of simple effects indicated that for the skilled subjects, the difference between sum and neutral targets was significant only at $60 \mathrm{msec}[F(1,100)=11.10$, $M S_{\mathrm{e}}=6,723, p<.011$. For the less skilled subjects, there were no significant differences between sum and neutral items. Thus, the results of this experiment provide only limited support for the hypothesis that skilled subjects would show larger effects of obligatory activation than would less skilled subjects. As discussed below, however, this conclusion is qualified by the high error rates at $40 \mathrm{msec}$ and by the cue type effects.

As in Experiment 1, ties $(797 \mathrm{msec}$ ) were rejected more slowly than standard $(776 \mathrm{msec})$ or plus-one cues $(759 \mathrm{msec})\left[F(2,40)=4.97, M S_{\mathrm{e}}=22,426, p<.02\right]$.

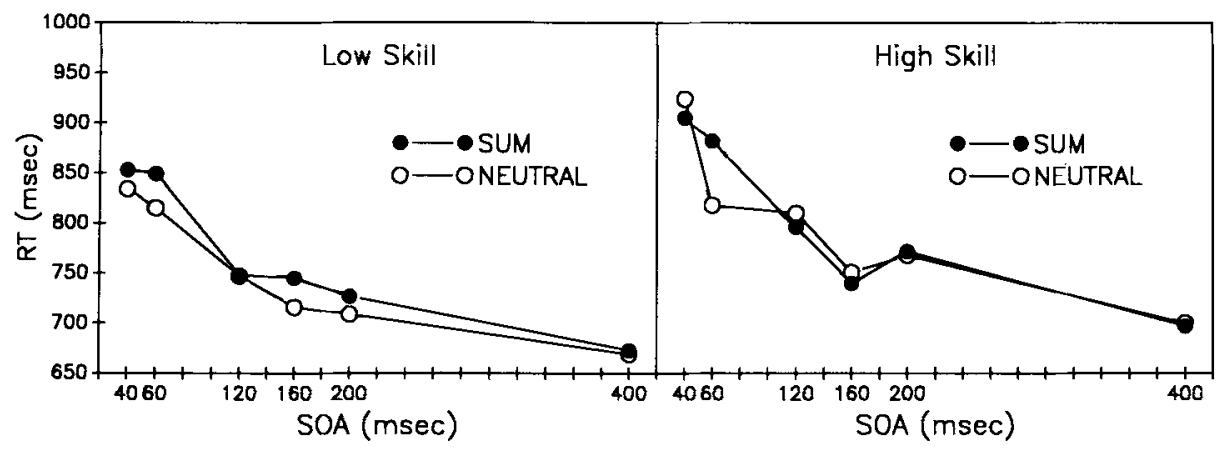

Figure 3. Latencies on sum and neutral problems by stimulus onset asynchrony in Experiment 2 for skilled and less skilled subjects. 


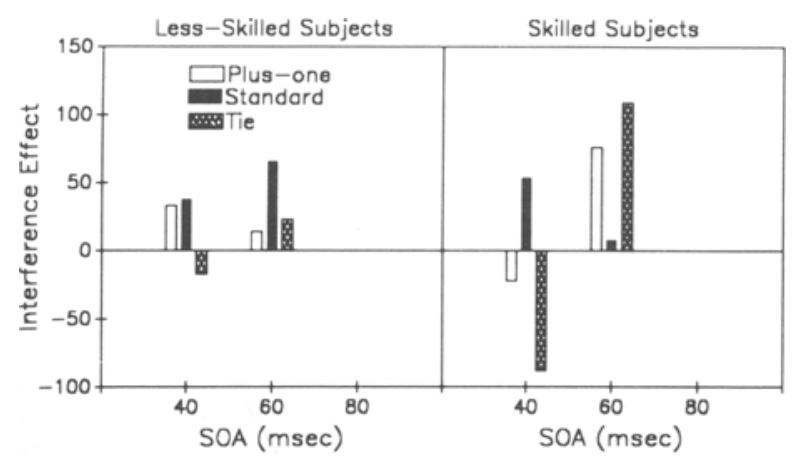

Figure 4. Interference effects (difference between sum and neutral latencies) for skilled and less skilled subjects by cue type and stimulus onset asynchrony in Experiment 2.

Cue type also interacted with SOA $[F(10,200)=2.66$, $\left.M S_{\mathrm{e}}=8,570, p<.05\right]$. Tie cues were rejected somewhat more slowly than standard or plus-one cues at 40 , 60 , and $120 \mathrm{msec}$ (Tukey HSD, ps $<.10, .10$, and .05, respectively). Latencies did not vary with cue type at the other SOAs (see Table 5). ${ }^{4}$

Skill interacted with cue type $\left[F(2,40)=4.10, M S_{\mathrm{e}}=\right.$ $22,426, p<.05]$, such that skilled subjects were slower on ties than less skilled subjects (836 vs. $759 \mathrm{msec})$ $\left[F(1,60)=4.08, M S_{\mathrm{e}}=104,123, p<.05\right]$, whereas the two groups did not differ on standard (778 vs. $773 \mathrm{msec}$ ) or plus-one items (776 vs. $739 \mathrm{msec})$. These cue type effects suggest that tie cues were processed somewhat differently from standard or plus-one cues. Because tie cues also showed differential effects in Experiment 1, the interaction of skill and target type was examined separately at each SOA for the three cue types (see Figure 4). At $40 \mathrm{msec}$, high error rates compromise any conclusions about latency differences (see Table 5). At $60 \mathrm{msec}$, however, there was a significant interaction between skill and target type for ties $\left[F(1,200)=5.6, M S_{\mathrm{e}}=9,035, p<\right.$ $.05]$. Thus, skilled subjects showed evidence for larger effects of obligatory activation than less skilled subjects only on items that were hypothesized to be most strongly associated in the addition network. Tests of simple effects indicated that there were significant differences between sum and neutral targets for skilled subjects on tie and plusone items at $60 \mathrm{msec}\left[F \mathrm{~s}(1,200)>3.84, M S_{\mathrm{e}}=9,035\right.$, $p s<.05]$. None of the differences were significant for less skilled subjects.

In summary, the results of this experiment provide qualified support for the hypothesis that skilled subjects show larger effects of obligatory activation than do less skilled subjects; the hypothesis was supported only for tie problems. Unlike in Experiment 1, interpretation of latency effects at the shortest SOA was compromised by high error rates. Cue type effects, as in Experiment 1, support a limited version of the specific accessibility hypothesis, in that tie cues were most likely to be activated.

\section{Discussion}

As in Experiment 1, sum targets were rejected more slowly than neutral targets at a short SOA $(60 \mathrm{msec})$. This interference effect was larger for the skilled than for the less skilled subjects only on tie problems. Thus, in contrast to the results of LeFevre et al. (1988), obligatory activation was not the same in the plus and in the blank conditions when skill was' considered. This conclusion must be qualified because, for skilled subjects, high error rates at the shortest SOA made latency effects difficult to interpret.

Why did the skilled subjects make such a large number of errors at the shortest SOA? Comparison of the latencies for the less skilled subjects across SOAs indicates that the less skilled subjects tended to be slower in Experiment 1 than in Experiment 2, and that the pattern of interference effects was similar in the two experiments. For these subjects, the effect of the plus sign may have been to increase encoding time, resulting in somewhat longer latencies (cf. LeFevre et al., 1988).

For the skilled subjects, however, latencies were very similar in both experiments across SOAs, with the exception of those at $40 \mathrm{msec}$. Thus, the additional symbol did not increase processing time and may have been processed automatically by skilled subjects. In comparison with the skilled subjects in Experiment 1, the skilled subjects in Experiment 2 had faster latencies on sums and slower latencies on neutral items at $\mathbf{4 0 ~ m s e c . ~ E r r o r ~ r a t e s ~}$ were substantial in both the sum and the neutral conditions at $40 \mathrm{msec}$. The absence of a plus sign may have made it difficult for the subjects to decide on the order of presentation of the three numbers. The plus sign signaled to the subjects which digits formed the cue and which digit was the target. For the skilled subjects, the activation of related digits, such as the sum, may have increased the difficulty of the task at the short SOAs.

The slow overall response latencies and large error rates on ties may be a product of the demands of the numbermatching task. This task requires the subject to (1) encode and activate the two digits in the cue, (2) encode and activate the target, (3) compare the results of (1) and (2) and decide whether a match occurred, and (4) respond. If the decision in (3) is based on relative activation levels, tie cues may be particularly hard to distinguish from "yes" problems. That is, any time that a digit receives a "double-dose" of activation (e.g., $3+2$ and 3 or $2+2$ and 6), the tendency may be to respond "yes." At longer SOAs, it would be easier to distinguish a matching problem from a "yes" problem on the basis of the order of digit presentation.

Alternatively, the slow overall response latencies and high error rates on ties may reflect properties of spreading activation within the associative network. In the network, activation is assumed to spread from the "parent" nodes to related nodes. In the case of a nontie problem (e.g., 2+5), activation will spread to two sets of arith- 
metic facts (e.g., facts associated with 2 and facts associated with 5). In the case of tie problems, however, activation will be concentrated within a single family of arithmetic facts. For example, in the problem $3+3$, facts associated with the number 3 will receive activation from both addends. Hence, in the case of tie problems, the level of activation associated with the sum may be more concentrated at one answer than is the case with nontie problems. At longer SOAs, it would be easier for subjects to inhibit this relatively high level of activation; at shorter SOAs, the high activation may produce elevated error rates. Inspection of the means for tie problems (see $\mathrm{Ta}$ bles 2 and 4) suggests that slower latencies to ties persist until at least $80 \mathrm{msec}$. Thus, the results of the present research suggest that tie problems show larger effects of obligatory activation than nonties do, and that the effect is partially contained in high error rates (especially in the blank condition) and in activation that persists longer than for nonties.

\section{GENERAL DISCUSSION}

In two experiments, we found evidence for obligatory activation of simple addition facts. Among skilled subjects, activation occurred quickly after encoding of a cue and produced interference at short SOAs, at least when a plus sign was presented. In contrast, less skilled subjects showed smaller effects of obligatory activation that were not statistically significant (cf. LeFevre et al., 1991). These findings accord with the view that the accessibility of basic arithmetic facts may be related to individual differences in arithmetic skill (Ashcraft et al., 1992; Kaye, 1986).

The present findings are consistent with research on other complex cognitive tasks in which automaticity is assumed to be a component of skill. For example, in reading, one current assumption is that automatic word recognition and syntactic processes make cognitive resources available that can then be devoted to the demands of comprehension (Just \& Carpenter, 1992; Perfetti, 1985). A similar effect may occur in arithmetic. Automatic retrieval of arithmetic facts may allow an individual to devote processing resources to the other aspects of complex arithmetic, such as carrying in multidigit addition. Widaman et al. (1989) proposed a model of multidigit addition in which carrying is a resource-demanding process. Because performance on multidigit problems is a combination of a number of processes, including encoding speed, memory access, and carrying, automaticity of memory access would provide a clear advantage to the problem solver. Although theorists have suggested that automaticity of retrieval is important in arithmetic skill (e.g., Ashcraft et al., 1992; Kaye, 1986; Resnick \& Ford, 1981), experimental evidence has been scarce (see, e.g., Kaye et al., 1989).

The results of Experiment 1 (plus sign included) are most consistent with the general accessibility view of automaticity for addition, at least for skilled subjects, although there is some evidence that tie activation persists longer than activation of other items. In Experiment 2, obligatory activation was most evident for ties (no plus sign), suggesting that the ties have the strongest connections in the addition network. This conclusion is consistent with the findings of a number of studies in which ties are responded to more quickly than comparable nonties in arithmetic tasks (Groen \& Parkman, 1972; Miller et al., 1984). According to a specific accessibility view, obligatory activation would be larger for those problem types that receive the most practice. Thus the results of the present research suggest that ties are the most accessible facts in the network for both skilled and less skilled subjects.

Although the present results provide only limited support for specific accessibility, we did not test all possible singledigit arithmetic problems. Response times in arithmetic tasks generally increase as a function of the size of the digits (Ashcraft \& Battaglia, 1978; Groen \& Parkman, 1972; Miller et al., 1984), and this increase in response time presumably reflects the accessibility of the various facts (Ashcraft, 1992; Koshmider \& Ashcraft, 1991). The largest minimum addend in the present studies was only four, however, and the largest changes in response times are typically found for minimum addends larger than 5 and sums greater than 10 (e.g., Ashcraft \& Stazyk, 1981; Miller et al., 1984). Thus, if the range of problem sizes was extended to problems with larger sums and larger minimum addends, stronger evidence for specific accessibility might be found. In accord with this view, Thibodeau and LeFevre (1993) recently found evidence for specific accessibility of multiplication facts in the numbermatching task. In their study, obligatory activation was only found on multiplication problems with products that were less than 30 . Because larger multiplication problems are presented less frequently and receive less practice than small multiplication problems (Ashcraft, 1992), Thibodeau and LeFevre's results suggest that the accessibility of multiplication facts varies across problems. Hence, resolution of the issue of whether addition facts vary in accessibility within the network awaits further research.

The present results support the hypothesis that automaticity of retrieval of arithmetic facts may be a source of individual differences in arithmetic skill. Obligatory activation (as an index of accessibility) varied across individuals, with skilled individuals showing large effects and less skilled individuals showing smaller effects. Although interference effects were not statistically significant for less skilled subjects, less skilled subjects did show small differences of approximately $45 \mathrm{msec}$ at the 60 - and 120 msec SOAs in Experiment 1, and of approximately $35 \mathrm{msec}$ at the 60- and 160-msec SOAs in Experiment 2. Thus, less skilled subjects may have connections between problems and sums that are not strong enough to produce substantial obligatory activation on a majority of trials. The speed of activation may also be slower for less skilled than for skilled subjects, as is indicated by the small interference effects at somewhat longer SOAs of 120 and $160 \mathrm{msec}$ in the present experiments, and at 120 and 
$500 \mathrm{msec}$ in LeFevre et al. (1991). One interpretation of our results is that individuals vary in the accessibility of their addition facts in such a way that skilled individuals show relatively strong and fast activation in comparison with less skilled subjects.

A more extreme interpretation of the present findings is that less skilled individuals have impoverished networks with very weak or nonexistent connections between many problems and their sums. This situation is found in children who are in the process of learning their arithmetic facts (e.g., Siegler \& Shrager, 1984). The present studies provided a very liberal test of automaticity, because these addition problems with sums less than 10 should be the most likely of all arithmetic facts to have strong connections between problems and sums. Furthermore, individuals who do not show evidence of obligatory activation on these problems would be unlikely to have accessible large addition facts. Thus, the present findings support the view that a substantial number of adults do not have complete and accessible arithmetic networks.

In summary, the view that a substantial number of adults do not have accessible arithmetic networks poses a serious challenge for extant network models of arithmetic knowledge (see also Ashcraft et al., 1992). All of these models include the assumption that the majority of adults have automatic, effortless retrieval of basic arithmetic facts (e.g., Ashcraft, 1987; Campbell \& Oliphant, 1992; Siegler, 1987; Widaman et al., 1989). Although models of arithmetic solution in children allow for nonretrieval processing (i.e., Siegler \& Shrager, 1984), models of arithmetic processing in adults have not been elaborated in this direction (e.g., Ashcraft, 1982). The present results, in combination with recent findings that many adults use counting or other reconstructive strategies on a substantial number of problems (Bisanz, 1992; Geary, Frensch, \& Wiley, 1993; Geary \& Wiley, 1991; LeFevre, Sadesky, \& Bisanz, 1994; Svenson, 1985; Widaman et al., 1992), suggest that models of adults' arithmetic processing may require elaboration and revision. Reconstructive strategies could be fast and automatic (Baroody, 1983, 1985 ), but they would not produce obligatory activation of the sort measured by the number-matching task. Thus, it may be necessary to seriously consider the role of nonretrieval processing in models of arithmetic performance in order to adequately describe the performance of adults at all levels of skill.

\section{REFERENCES}

Ashcraft, M. H. (1982). The development of mental arithmetic: A chronometric approach. Developmental Review, 2, 213-236.

ASHCRAFT, M. H. (1987). Children's knowledge of simple arithmetic: A developmental model and simulation. In J. Bisanz, C. J. Brainerd, \& R. Kail (Eds.), Formal methods in developmental psychology: Progress in cognitive development research (pp. 302-338). New York: Springer-Verlag.

ASHCRAFT, M. H. (1990). Strategic processing in children's mental arithmetic: A review and proposal. In D. F. Bjorklund (Ed.), Children's strategies: Contemporary views of cognitive development ( $\mathrm{pp} .185-$ 212). Hillsdale, NJ: Erlbaum
AshCraft, M. H. (1992). Cognitive arithmetic: A review of data and theory. Cognition, 44, 75-106.

AshCraft, M. H., \& Battaglia, J. (1978). Cognitive arithmetic: Evidence for retrieval and decision processes in mental addition. Journal of Experimental Psychology: Human Learning \& Memory, 4, 527-538.

Ashcraft, M. H., Donley, R. D., Halas, M. A., \& Vakali, M. (1992). Working memory, automaticity, and problem difficulty. In J. I. D. Campbell (Ed.), The nature and origins of mathematical skills (pp. 301-329). Amsterdam: Elsevier.

AshCRaft, M. H., \& Fierman, B. A. (1982). Mental addition in third, fourth, and sixth graders. Journal of Experimental Child Psychology, 33, 216-234.

Ashcraft, M. H., \& StazyK, E. H. (1981). Mental addition: A test of three verification models. Memory \& Cognition, 9, 185-196.

Baroody, A. J. (1983). The development of procedural knowledge: An alternative explanation for chronometric trends of mental arithmetic. Developmental Review, 3, 225-230.

BAROODY, A. J. (1985). Mastery of the basic number combinations: Internalization of relationships or facts? Journal for Research in Mathematics Education, 16, 83-98.

BISANZ, J. (1992, May). Lessons from arithmetic: Influences on the selection of problem-solving procedures. Paper presented at the Banff Annual Seminar in Cognitive Science, Banff, AB, Canada.

CAMpBelL, J. I. D. (1987a). Network interference and mental multiplication. Journal of Experimental Psychology: Learning, Memory, \& Cognition, 13, 109-123.

Campbell, J. I. D. (1987b). Production, verification, and priming of multiplication facts. Memory \& Cognition, 15, 349-364.

CampBell, J. I. D. (1991). Conditions of error priming in numberfact retrieval. Memory \& Cognition, 19, 197-209.

Campbell, J. I. D., \& ClaRK, J. M. (1989). Time course of error priming in number-fact retrieval: Evidence for excitatory and inhibitory mechanisms. Journal of Experimental Psychology: Learning, Memory, \& Cognition, 15, 920-929.

Camprell, J. I. D., \& Graham, D. J. (1985). Mental multiplication skill: Structure, process, and acquisition. Canadian Joumal of $P$ sychology, 39, 338-366.

Campbell, J. I. D., Oliphant, M. (1992). Representation and retrieval of arithmetic facts: A network-interference model and simulation. In J. I. D. Campbell (Ed.), The nature and origin of mathematical skills (pp. 331-364). Amsterdam: Elsevier.

French, J. W., Ekstrom, R. B., \& Price, I. A. (1963). Kit of reference tests for cognitive factors. Princeton, NJ: Educational Testing Service.

Geary, D. C., Frensch, P. A., \& Wiley, J. G. (1993). Simple and complex mental subtraction: Strategy choice and speed-of-processing differences in younger and older adults. Psychology \& Aging, 8, 242-256.

Geary, D. C., \& Widaman, K. F. (1987). Individual differences in cognitive arithmetic. Journal of Experimental Psychology: General, 116, 154-171.

Geary, D. C., Widaman, K. F., \& Little, T. D. (1986). Cognitive addition and multiplication: Evidence for a single memory network. Memory \& Cognition, 14, 478-487.

Geary, D. C., \& Wiley, J. G. (1991). Cognitive addition: Strategy choice and speed-of-processing differences in young and elderly adults. Psychology \& Aging, 6, 474-483.

Groen, G. J., \& ParkMAN, J. M. (1972). A chronometric analysis of simple addition. Psychological Review, 79, 329-343.

HamanN, M. S., AshCraft, M. H. (1985). Simple and complex mental addition across development. Journal of Experimental Child Psychology, 40, 49-72.

Hamann, M. S., \& Ashcraft, M. H. (1986). Textbook presentations of the basic arithmetic facts. Cognition \& Instruction, 3, 173-192.

HASHER, L., \& ZACKs, R. T. (1979). Automatic and effortful processes in memory. Journal of Experimental Psychology: General, 108, 356-388.

Just, M. A., \& CARPENTER, P. A. (1992). A capacity theory of comprehension: Individual differences in working memory. Psychological Review, 99, 122-149. 
KAYE, D. B. (1986). The development of mathematical cognition. Cognitive Development, 1, 157-170.

Kaye, D. B., DeWinstanley, P., Chen, Q., \& Bonnefil, V. (1989). Development of efficient arithmetic computation. Journal of Educational Psychology, 81, 467-480.

Koshmider, J. W., \& AshCraft, M. H. (1991). The development of children's mental multiplication skills. Journal of Experimental Child Psychology, 51, 53-89.

LeFEvre, J., \& BisAnz, J. (1986). A cognitive analysis of number-series problems: Sources of individual differences in performance. Memory \& Cognition, 14, 287-298.

LeFevre, J., \& Bisanz, J. (1987, April). Cognitive arithmetic: Evidence for the development of automaticity. Paper presented at the biennial meeting of the Society for Research in Child Development, Baltimore.

LeFevre, J., Bisanz, J., \& Mrkonjic, L. (1988). Cognitive arithmetic: Evidence for obligatory activation of arithmetic facts. Memory \& $\mathrm{Cog}$ nition, 16, 45-53.

LeFevre, J., Kulak, A. G., \& Bisanz, J. (1991). Individual differences and developmental change in the associative relations among numbers. Journal of Experimental Child Psychology, 52, 256-274.

LeFeVre, J., SAdesky, G., \& Bisanz, J. (1994). Selection of procedures in mental addition: Reassessing the problem-size effect in adults. Manuscript submitted for publication.

LogAN, G. D. (1985). Skill and automaticity: Relations, implications, and future directions. Canadian Journal of Psychology, 39, 367-386.

LoGAN, G. D. (1988). Toward an instance theory of automatization. Psychological Review, 95, 492-527.

Miller, K. F., \& Paredes, D. R. (1990). Starting to add worse: Effects of learning to multiply on children's addition. Cognition, 37, 213-242.

Miller, K. F., Perlmutter, M., \& Keating, D. (1984). Cognitive arithmetic: Comparison of operations. Journal of Experimental Psychology: Learning, Memory, \& Cognition, 10, 46-60.

PerfetTI, C. A. (1985). Reading ability. New York: Oxford University Press.

RESNICK, L. B., \& FORD, W. W. (1981). The psychology of mathematics for instruction. Hillsdale, $\mathrm{NJ}$ : Erlbaum.

SHIFFRIN, R. M., \& SCHNEIDER, W. (1977). Controlled and automatic human information processing: II. Perceptual learning, automatic attending, and a general theory. Psychological Review, 84, 127-190.

SIEGLER, R. S. (1987). The perils of averaging over strategies: An example from children's addition. Journal of Experimental Psychology. General, 116, 250-264.

SIEGLER, R. S. (1988). Strategy choice procedures and the development of multiplication skill. Journal of Experimental Psychology: General, 117, 258-275.

Siegler, R. S., \& Jenkins, E. A. (1989). How children discover new strategies. Hillsdale, NJ: Erlbaum.

SiEgler, R. S., \& Shrager, J. (1984). Strategy choices in addition and subtraction: How do children know what to do? In C. Sophian (Ed.), Origins of cognitive skills (pp. 229-293). Hillsdale, NJ: Erlbaum.

Stanners, R. F., Jastrembski, J. E., \& Westbrook, A. (1975). Fre- quency and visual quality in a word-non-word classification task. Journal of Verbal Learning \& Verbal Behavior, 14, 259-264.

Stazyk, E. H., Ashcraft, M. H., \& Hamann, M. S. (1982). A network approach to simple multiplication. Journal of Experimental Psychology: Learning, Memory, \& Cognition, 8, 320-335.

SVEnson, O. (1985). Memory retrieval of answers of simple additions as reflected in response latencies. Acta Psychologica, 59, 285-304.

ThibodeAu, M. H., \& LeFevre, J. (1993). The accessibility of multiplication facts. Manuscript submitted for publication.

Widaman, K. F., Geary, D. C., Cormier, P., \& Little, T. D. (1989). A componential model for mental addition. Journal of Experimental Psychology: Learning, Memory, \& Cognition, 15, 898-919.

Widaman, K. F., LitTle, T. D., Geary, D. C., \& Cormier, P. (1992). Individual differences in the development of skill in mental addition: Internal and external validation of chronometric models. Learning \& Individual Differences, 4, 167-213.

Winkelman, J. H., \& SCHMidt, J. (1974). Associative confusions in mental arithmetic. Journal of Experimental Psychology, 102, 734-736.

ZBRodoff, N. J., \& LoGAN, G. D. (1986). On the autonomy of mental processes: A case study of arithmetic. Journal of Experimental Psychology: General, 115, 118-130.

\section{NOTES}

1. The results for mean and median latencies were essentially the same. 2. There were no main effects of sex, although sex did interact with cue and SOA $\left[F(10,200)=3.07, M S_{\mathrm{e}}=9,769, p<.01\right]$. Males had much slower latencies for tie cues than for standard or plus-one cues at the $40-$ and $60-\mathrm{msec}$ SOAs. Females, however, showed slower tie latencies at $80 \mathrm{msec}$ and somewhat faster plus-one latencies at all SOAs after $40 \mathrm{msec}$. The slight confounding of sex and skill makes these isolated effects of sex difficult to interpret.

3. There was also a significant interaction between sex, target type, and cue type $\left[F(2,40)=5.08, M S_{\mathrm{e}}=85.3, p<.05\right]$. Females made more errors to tie cues than standard or plus-one cues for both sum $(11.9 \%, 4.7 \%$, and $3.3 \%$, respectively) and neutral targets $(13.5 \%$, $4.0 \%$, and $3.3 \%$ ). Males also made more errors to ties than standard or plus-one cues on sum targets $(15.6 \%, 7.5 \%$, and $3.3 \%)$; on neutral targets, however, errors to ties and plus-one cues were not significantly different $(11.6 \%$ vs. $7.5 \%)$, although ties were solved less accurately than standard cues $(5.0 \%$; Tukey HSD, $p<.05)$.

4. Cue type also interacted with $\operatorname{sex}\left[F(2,40)=4.01, M S_{\mathrm{e}}=22,426\right]$; females rejected tie cues $(824 \mathrm{msec})$ more slowly than standard $(771 \mathrm{msec})$ or plus-one cues $(755 \mathrm{msec}$; Tukey HSD, $p<.05)$. For males, latencies for tie cues $(771 \mathrm{msec})$ did not differ from those for standard $(781 \mathrm{msec}$ ) or plus-one cues $(761 \mathrm{msec})$. As in Experiment 1 , these isolated effects of sex are difficult to interpret. Because they do not directly pertain to the present hypotheses, they are not discussed further.

(Manuscript received March 1, 1993; revision accepted for publication July 28,1993 .) 